\section{SOI: $1.1 /$ TAS DOI: $10.15863 / \mathrm{TAS}$ International Scientific Journal Theoretical \& Applied Science}

p-ISSN: 2308-4944 (print) e-ISSN: 2409-0085 (online)

Year: $2016 \quad$ Issue: 1 Volume: 33

Published: $30.01 .2016 \quad$ http://T-Science.org

SECTION 7. Mechanics and machine construction.

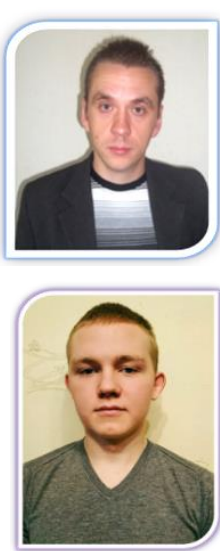

Denis Alexandrovich Chemezov Master of Engineering and Technology, Corresponding member of International Academy of Theoretical and Applied Sciences, Lecturer of Vladimir Industrial College, Russian Federation chemezov-da@yandex.ru

Nikita Andreevich Palev Student of Vladimir Industrial College, Russian Federation nik-palev@yandex.ru

\title{
INJECTION MOLDING OF A PLASTIC GEAR WHEEL DURING THE CHANGE OF THE TECHNOLOGICAL MODES OF PROCESS
}

Abstract: The article presents the analysis of time of the molten material is filled in the mold for production of cylindrical gear wheel when changing temperature modes of the technological process.

Key words: injection molding, molding time, a gear wheel, a plastic, temperature.

Language: Russian

Citation: Chemezov DA, Palev NA (2016) INJECTION MOLDING OF A PLASTIC GEAR WHEEL DURING THE CHANGE OF THE TECHNOLOGICAL MODES OF PROCESS. ISJ Theoretical \& Applied Science, 01 (33): 31-34.

Soi: http://s-o-i.org/1.1/TAS-01-33-7 Doi: crossef http://dx.doi.org/10.15863/TAS.2016.01.33.7

УДК 621.74.043.2

\section{ИНЖЕКЦИОННОЕ ЛИТЬЕ ПЛАСТИКОВОГО ЗУБЧАТОГО КОЛЕСА ПРИ ИЗМЕНЕНИИ ТЕХНОЛОГИЧЕСКИХ РЕЖИМОВ ПРОЦЕССА}

Аннотация: В статье представлен анализ времени заполнения расплавленным материалом литейной формы для изготовления ичлиндрического зубчатого колеса при изменении температурных режимов технологического прочесса.

Ключевые слова: инжекционное литье, время литья, зубчатое колесо, пластик, температура.

Зубчатые колеса, находящиеся в зацеплении и имеющие различное по скорости вращательное движение для преобразования (увеличение или уменьшение) крутящего момента и числа оборотов валов на входе и выходе, называются зубчатой передачей [1].

Выбор материалов зубчатых колес зависит от условий эксплуатации механической передачи. В качестве материалов могут применяться металлические сплавы для средне- и тяжелонагруженных зубчатых колес и неметаллические материалы - для малонагруженных зубчатых колес [2]. Ограниченное применение пластмассовых зубчатых колес компенсируется быстроходностью и бесшумностью работы передачи, высокой износостойкостью зубьев при отсутствии смазки между контактными поверхностями, а также устойчивостью в агрессивных средах.
Все способы изготовления зубчатых колес можно разделить на механическую обработку заготовки лезвийными и абразивными режущими инструментами, обработку давлением заготовки в холодном и горячем состоянии и литье под давлением (инжекционное литье) [3]. Инжекционное литье является высокопроизводительным способом получения зубчатого колеса из пластмассы (пластика). На качество отливки будет влиять равномерность заполнения материалом литейной формы (месторасположение инжекции, скорость впрыска и температура материала, конфигурация и степень точности изготовления формы и др.). Так как наиболее нагруженными и точными элементами детали являются зубья, то исследование процесса инжекционного литья при различных температурах расплавленного материала позволит определить время и полноту заполнения формы на более ответственных участках. 
Для расчета были приняты следующие параметры цилиндрического прямозубого зубчатого колеса [4]: количество зубьев $z-17$; модуль $m-5.5$ мм; диаметр делительной окружности $d-93.5$ мм; диаметр окружности вершин $d_{a}-104.5$ мм; диаметр окружности впадин $d_{f}-79.75$ мм; высота головки зуба $h_{a}-5.5$ мм; высота ножки зуба $h_{f}-6.875$ мм; полная высота зуба $h-12.375$ мм; шаг зацепления колеса $P_{t}-17.27$ мм; толщина зуба $S_{t}-8.635$ мм; ширина зуба $b_{3}-12$ мм; ширина впадины $E_{t}-8.635$ мм; толщина зуба по окружности вершин $S_{a}-4.7$ мм; радиус сопряжения во впадине зуба $r_{c}-0.3$ мм; фаска на зубьях и в посадочном отверстии $-1.2 \times$ $45^{\circ}$; диаметр посадочного отверстия $d_{6}-32.8$ мм; ширина шпоночного паза $b_{u}-9$ мм; глубина шпоночного паза $t_{l}-4.5$ мм; радиус закругления шпоночного паза $r-0.5$ мм.

Общий вид объемной твердотельной модели цилиндрического зубчатого колеса представлен на рис. 1.

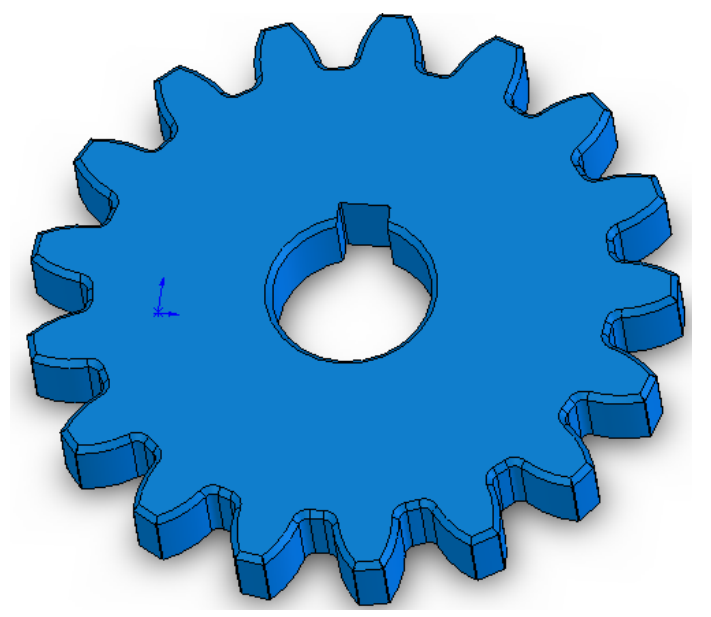

Рисунок 1 - Объемная твердотельная модель цилиндрического зубчатого колеса.

Зубчатое колесо изготавливалось методом инжекционного литья. Моделирование процесса литья зубчатого колеса выполнялось в модуле MoldflowXpress программной среды SolidWorks [5, 6]. Модуль позволяет выполнять моделирование потока пластика начального уровня с одной точкой литья. По результатам расчета можно определять заполнение детали на основе параметров геометрии, применяемого материала и выбранной точки инжекционного литья.

В модуле MoldflowXpress выполнялись следующие действия по установке начальных условий процесса литья:

1. На модели цилиндрического зубчатого колеса задавалась точка (рис. 2, а) определяющая местоположение инжекции (во вкладке «Отлив» отображение координат точки по трем координатным осям). Точка выбрана на торцевой поверхности зубчатого колеса в области наиболее нагруженных элементов детали.

2. Выбор материала в одноименной вкладке. Материалом отливки принимался полиоксиметилен (РОМ) - полуфабрикат, относящийся к группе технических термопластов. Выбор материала обуславливался высокой способностью сохранения формы, упругостью и незначительным впитыванием влаги. РОМ обладает следующими физикомеханическими свойствами [7]: твердость -82

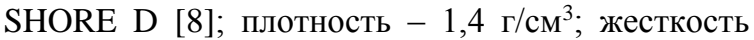
при шаровом давлении - $135 \mathrm{H} / \mathrm{Mм}^{2}$; натяжение при вытягивании - $62 \mathrm{H} / \mathrm{Mм}^{2}$; растяжение при вытягивании $-8 \ldots 10 \%$; прочность на растяжение - 40\%; ударная вязкость при $+23^{\circ} \mathrm{C}-70$ кДж/ $\mathrm{M}^{2}$; ударная вязкость при $-30^{\circ} \mathrm{C}-40$ кДж/ $/ \mathrm{M}^{2}$; коэффициент трения (на сухую против стали, динамический) - 0,17 - 0,43; минимальная температура применения $--50^{\circ} \mathrm{C}$; максимальная температура применения $-+100^{\circ} \mathrm{C}$.

3. Выбор условий процесса инжекционного литья. Для 7 компьютерных экспериментов по определению времени литья зубчатого колеса температура литейной формы оставалась постоянной и составляла $90^{\circ} \mathrm{C}$. Температура расплавленного материала изменялась в диапазоне $180 \ldots 240^{\circ} \mathrm{C}$ с шагом $10^{\circ} \mathrm{C}$.

4. Сохранение данных и запуск анализа течения пластического материала в литейной форме. Время литья определяется после расчета.

Результаты моделирования инжекционного литья цилиндрического зубчатого колеса при температуре материала $210^{\circ} \mathrm{C}$ представлены в виде интерактивных эпюр на рис. 2, б - 3 .

ISPC Perspectives in science for 2016, 


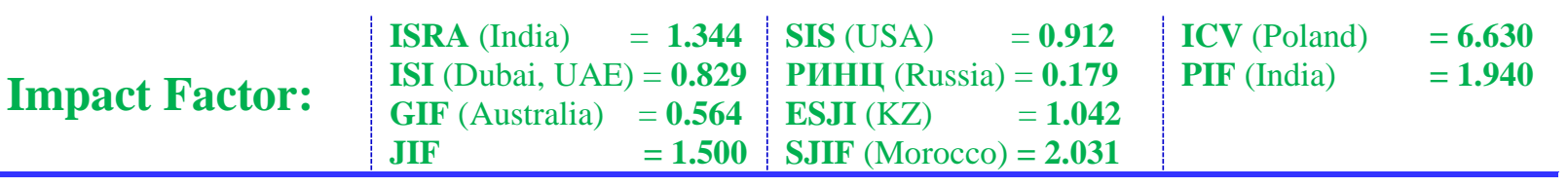
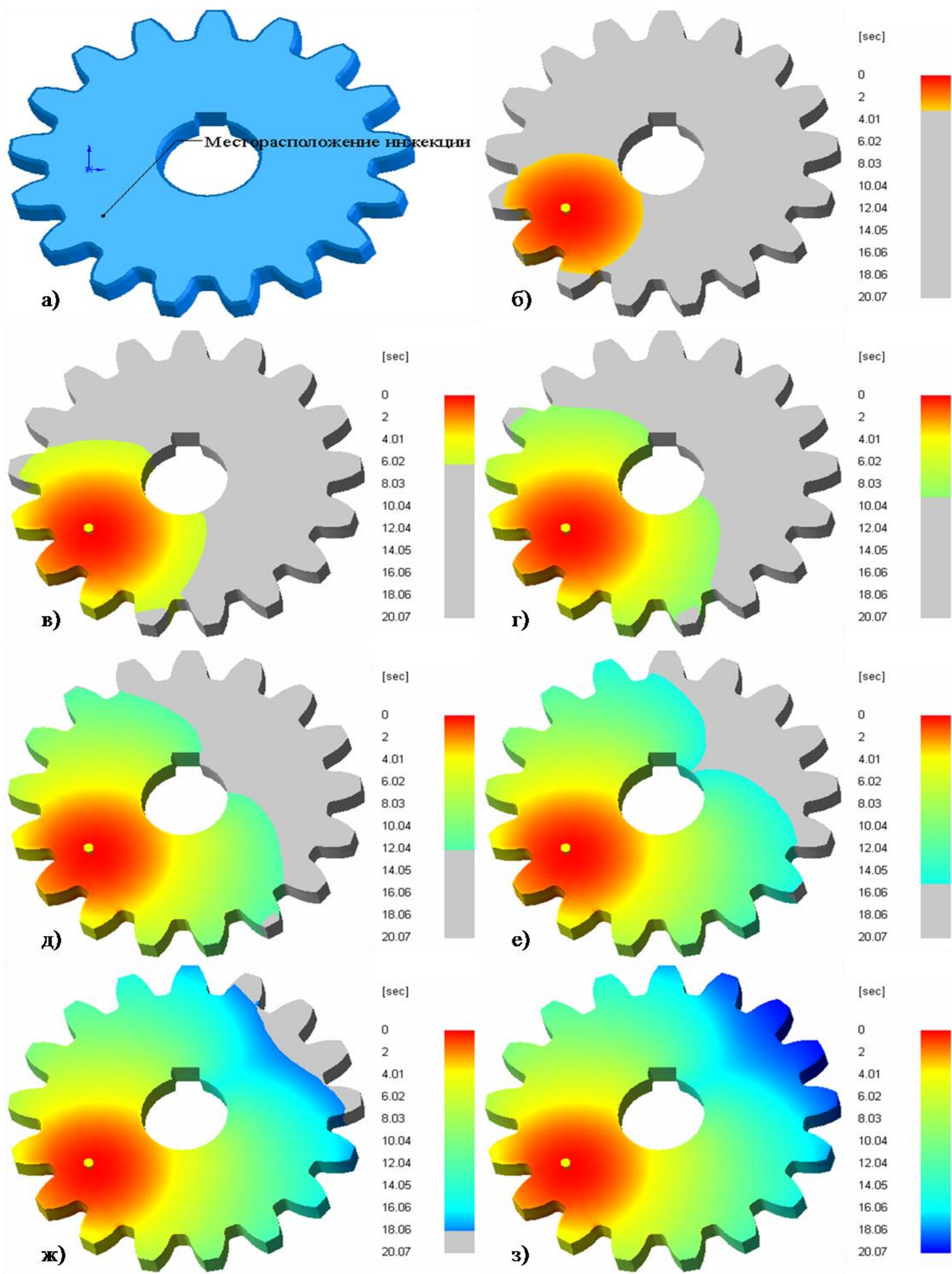

Рисунок 2 - Результаты компьютерного моделирования процесса литья цилиндрического зубчатого колеса при температуре материала $210^{\circ} \mathrm{C}:$ а - месторасположение инжекции расплавленного пластика; б - заполнение литейной формы материалом на $15 \%$; в - заполнение литейной формы материалом на $30 \%$; г - заполнение литейной формы материалом на 45\%; д - заполнение литейной формы материалом на $60 \%$; $\mathrm{e}$ - заполнение литейной формы материалом на $75 \%$; ж - заполнение литейной формы материалом на 90\%; 3 - заполнение литейной формы материалом на $100 \%$. 
Процесс литья визуально отображается на модели детали цветовыми контурами. Цвет контура показывает последовательность заполнения литейной формы и характер течения пластика через деталь: красный указывает первую область заполнения, синий - последнюю область заполнения.

Зубья колеса заливаются пластиком в полном объеме. Однако, температура пластика в симметрично выливаемых зубьях колеса будет меньше, чем в зубьях, расположенных в области впрыска материала.

В целом деталь легко и полностью заливается, качество приемлемое при текущей точке инжекционного литья.

Расчетное время литья зубчатого колеса при различных температурных режимах представлено в табл. 1 .

Таблица 1

Время литья зубчатого колеса при изменении температуры расплавленного материала.

\begin{tabular}{|c|c|c|}
\hline Tемпература материала, ${ }^{\circ} \mathrm{C}$ & Температура литейной формы, ${ }^{\circ} \mathrm{C}$ & Время литья, с \\
\hline 180 & \multirow{5}{*}{} & 30.1 \\
\hline 190 & & 25.07 \\
\hline 200 & \multirow{5}{*}{90} & 25.08 \\
\hline 210 & & 20.07 \\
\hline 220 & & 20.06 \\
\hline 230 & & 19.06 \\
\hline 240 & & 18.06 \\
\hline
\end{tabular}

C увеличением температуры пластика уменьшается время литья зубчатого колеса. Это связано с уменьшением вязкости и увеличением скорости течения материала в литейной форме. На температурных интервалах $180-190^{\circ} \mathrm{C}$ и 200 $210^{\circ} \mathrm{C}$ наблюдается сокращение времени литья детали на 5 с. Производительность процесса инжекционного литья не изменяется на интервалах $190-200^{\circ} \mathrm{C}$ и $210-220^{\circ} \mathrm{C}$. При температуре материала более $220^{\circ} \mathrm{C}$ время литья сокращается на 1 с.
Таким образом, наиболее рациональный температурный режим инжекционного литья зубчатого колеса будет составлять $210-220^{\circ} \mathrm{C}$ для материала и $90^{\circ} \mathrm{C}$ для литейной формы. Увеличение или уменьшение температуры материала не рекомендуется для технологического процесса инжекционного литья, так как это может привести к изменению химического состава и механических свойств, требуемых для данной детали.

\section{References:}

1. (2016) Zubchatye peredachi. Available: http://cherch.ru/mechanicheskie_peredachi/zub chatie peredachi.html (Accessed: 10.01.2016).

2. (2016) Materialy i termoobrabotka zubchatyh koles. Available:

http://www.webrarium.ru/transmissionmaterial.html (Accessed: 10.01.2016).

3. (2016) Tehnologichesky protsess izgotovleniya detaley iz termoplastov lit'em pod davleniem Available:

http://tehproplast.ru/technology\%20injection\%2 0molding.html (Accessed: 10.01.2016).

4. GOST 16531-83. Cylindrical gears. Terms, definitions and symbols.

5. Timur M, Demir C (2012) The mold design and analysis of cremaer body used in milking machines with solid works-moldflow $\mathrm{x}$ press program. Erciyes University journal of the Institute of Science and Technology 28(2): 122 $-129$.

6. (2016) Sistema avtomatizirovannogo proektirovaniya SolidWorks. Available: http://seniga.ru/index.php/sapr/ssapr/62solidworks.html (Accessed: 10.01.2016).

7. (2016) POM. Available: http://www.dpva.info/Guide/GuideMatherials/R esinesElastomersPlasticsPolimers/DiscriptionOf Elastomers/POM/ (Accessed: 10.01.2016).

8. (2016) Shore (Durometer) Hardness Testing of Plastics.

Available:

http://www.matweb.com/reference/shorehardness.aspx (Accessed: 10.01.2016). 